\title{
The second "time-out": a surgical safety checklist for lengthy robotic surgeries
}

\author{
Joseph B Song, Goutham Vemana, Jonathan M Mobley and Sam B Bhayani
}

\begin{abstract}
Robotic surgeries of long duration are associated with both increased risks to patients as well as distinct challenges for care providers. We propose a surgical checklist, to be completed during a second "time-out", aimed at reducing peri-operative complications and addressing obstacles presented by lengthy robotic surgeries. A review of the literature was performed to identify the most common complications of robotic surgeries with extended operative times. A surgical checklist was developed with the goal of addressing these issues and maximizing patient safety. Extended operative times during robotic surgery increase patient risk for position-related complications and other adverse events. These cases also raise concerns for surgical, anesthesia, and nursing staff which are less common in shorter, non-robotic operations. Key elements of the checklist were designed to coordinate operative staff in verifying patient safety while addressing the unique concerns within each specialty. As robotic surgery is increasingly utilized, operations with long surgical times may become more common due to increased case complexity and surgeons overcoming the learning curve. A standardized surgical checklist, conducted three to four hours after the start of surgery, may enhance perioperative patient safety and quality of care.
\end{abstract}

\section{Introduction}

Robotic surgery has become an increasingly adopted technology. Improved dexterity in narrow spaces and faster patient recovery are just some of the advantages cited in favor of adopting this new approach. After initial applications in gynecologic and urologic surgeries, robotic operations are now becoming more common. Indeed, robotic prostatectomy is currently estimated to be the most used method for radical prostatectomy in the United States [1] and robotic surgeries are being more frequently utilized in general and thoracic surgeries [2,3].

As most practicing surgeons have not had extensive training in robotic surgery, the learning curve may be heterogeneous. Additionally, as complex operations are often embraced with robotics, longer operating room (OR) times are common in the early experience $[4,5]$. These prolonged operations can be a challenge on many fronts. Not only do they exacerbate surgeon fatigue, but long cases also complicate nursing and anesthetic care. Furthermore, extended cases can put the patient at increased risk for position-related patient complications

\footnotetext{
* Correspondence: bhayanisa@wudosis.wustl.edu

Washington University in St. Louis School of Medicine, 4960 Children's Place, Campus Box 8242, St. Louis MO 63110, USA
}

such as peri-operative peripheral nerve injury and rhabdomyolysis $[6,7]$.

Indeed, patient positioning in extended robotic operations is of particular concern in regards to patient safety. Many robotic operations involve positioning of patients in angles that may not be well studied. For example, a tendency to exaggerate the Trendelenberg position during gynecologic and urologic robotic operations has been shown to increase intraocular pressure [8]. Patient positioning is further complicated by factors which make shifts in position difficult to notice. Not only do robotic arms partially obscure the patient, but surgeons perform these operations somewhat dissociated from the patient, as they sit at a console away from the bedside. Positioningrelated complications ranging from neuropathy to blindness have been reported after robotic surgery $[9,10]$.

Complications such as those mentioned above can be challenging to address. However, since the World Health Organization published its surgical checklist in 2008, part of which includes a pre-operative "time-out", checklists have been proven effective in decreasing perioperative morbidity and mortality [11]. To identify and possibly prevent some of the complications associated with extended robotic surgeries, we propose a "second time-out" - a checklist conducted three to four hours 
after the start of surgery (Figure 1). This "second timeout" is designed to assess patient safety in this unique surgical environment, particularly during the initial learning curve and with complex procedures. Furthermore, this checklist is designed to promote communication between the surgical, anesthetic and nursing staff while addressing specialty concerns which disproportionately impact patient care during prolonged robotic operations.

\section{Methods}

Analysis of the literature was performed, particularly addressing robotic operations with prolonged OR times. Based on this review, a checklist was developed to intervene on these issues prior to them becoming adverse events. Pubmed.gov was searched for articles containing the word "prolonged", "extended", "time", "duration", "complication(s)", "position(ing)", "concern(s)", "injury" or "injuries" along with the term "robotic" in the title. A total of 200 Pubmed articles fit the preliminary search criteria, of which 23 were appropriate for this study. The 23 articles reviewed were then used to further expand the search with the specific complications and concerns identified.

\section{Checklist components}

Suggestions from the literature were scrutinized and the second time-out was developed and categorized based on general areas that should be addressed by different members of the team. Four separate areas were incorporated: general patient factors, surgeon factors, anesthesia factors, and nursing factors (Figure 1). This design allowed the checklist to be cognizant of the specialized concerns of each staff's expertise while simultaneously engaging the entire team.

\section{General patient considerations}

Because robotic surgery is associated with specific positions such as steep Trendelenberg, location of the surgeon away from the operating table, and obscuration of the patient by robotic arms and extended draping, it is suggested that patient positioning be reviewed for shifts which may have gone unnoticed during long cases. This should be done with the room lights turned on, though the robot arms can remain docked and patient remain draped. All care providers should participate in reviewing patient positioning, though the need to maintain surgical sterility will limit how involved certain providers can be. Patients should be examined underneath their draping for proper extremity placement and padding. Particular attention should be paid to pressure points of the arms and legs. Any mottled appearance should be noted, which may be suggestive of rhabdomyolysis.

One of the most common results of improper patient positioning is nerve injury, which accounts for almost one third of anesthesia-related medical-legal claims in the US [12]. The effects of positioning changes are further compounded in long surgeries, as even one extra hour can significantly increase the risk of nerve damage [13]. Therefore, the second time-out serves as an invaluable opportunity to identify and prevent this potential issue.

While a full review of patient positioning is outside the scope of this paper, we have compiled a list of the
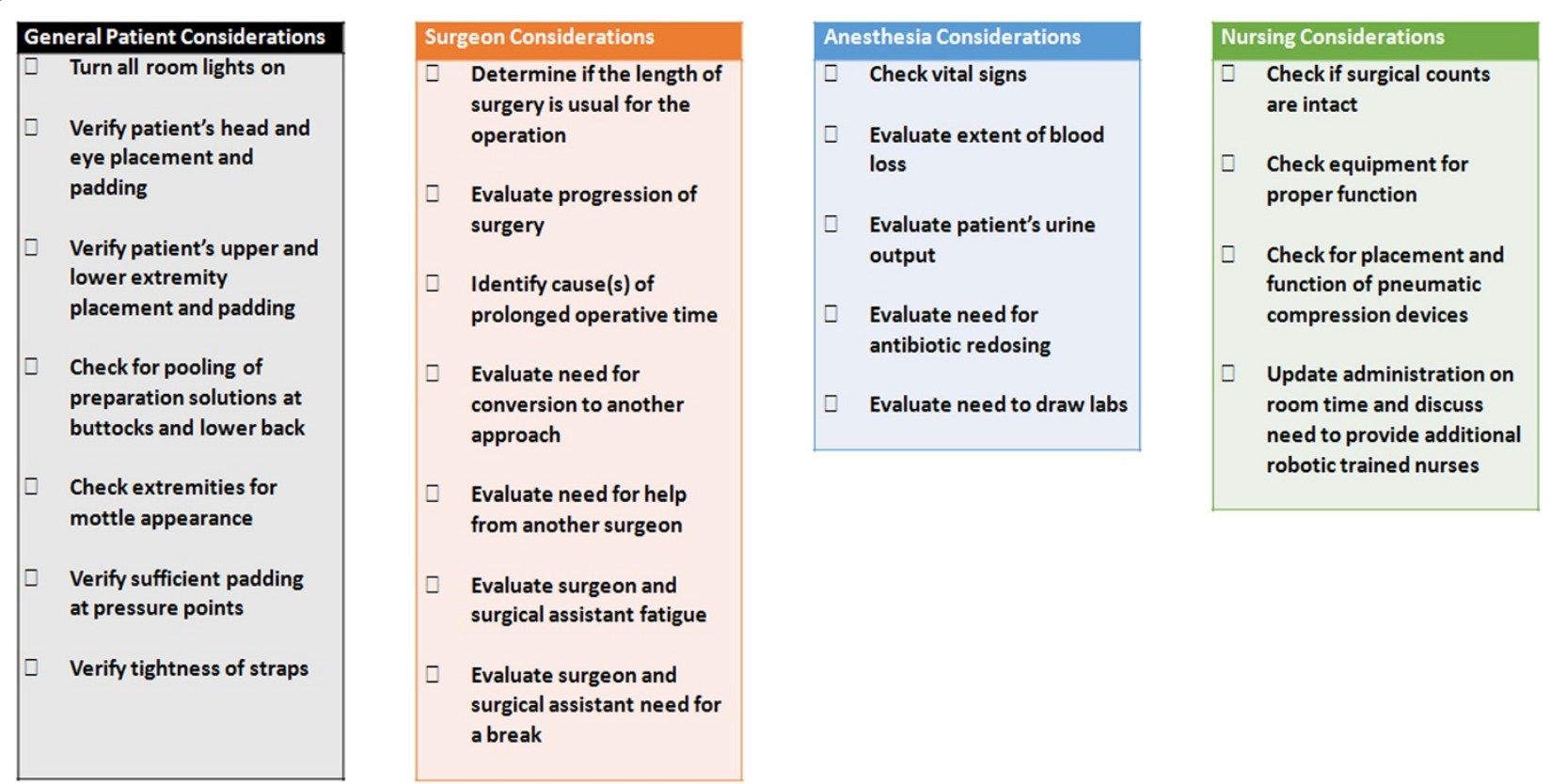

Figure 1 Checklist for a second time-out in extended robotic surgeries. 
most commonly injured nerves during robotic surgery (Figure 2). Firstly, commonly injured nerves in the upper extremity should be checked. This includes the ulnar nerve, which is frequently impinged when the arm is in a pronated position with the patient supine [14]. Elbow padding should be verified and, in cases where the elbow is flexed, elbow flexion should be decreased to less than $90^{\circ}$ [15]. Furthermore, the brachial plexus should be protected by minimizing stretching and extension of arms. This is especially important in the Trendelenberg position, as cephalad shifts in position can increase pressure on the brachial plexus, especially the upper trunk [16]. In this position, the use of shoulder braces has been associated with brachial plexus injury [9]. If shoulder braces are used, it should be verified that they are placed over the acromio-clavicular joint $[17,18]$. Lower extremity positioning should also be re-checked, especially if the patient is in a lithotomy position. In these cases, injuries to the common peroneal and saphenous nerves are known to occur due to contact between the fibular head and medial tibial condyle, respectively, with the stirrups or leg brace [19]. Furthermore, the degree of hip flexion and angulation should be checked as improper positioning can cause injury to the obturator and femoral nerves [20]. If any signs of patient displacement are found, a break in the steep Trendelenburg positioning can allow for proper assessment and repositioning.

Non-neurologic complications of improper patient positioning can also be addressed during the second timeout. Corneal abrasions have been reported as the most frequent ocular complication in the peri-operative period [21], so proper taping of the eyes and placement and padding of the head should be verified. The tightness of straps should be re-checked for increased pressures caused by shifts in patient positioning. This is especially important in the upper and lower extremities, where over-tucking can lead to compartment syndrome [15]. The buttocks and lower back should also be check for pooling of preparation solutions, which can cause chemical burns over long periods of time [22].

\section{Surgical considerations}

In extended cases, surgeons may become out of sync with operative time. This is especially true in robotic surgeries, where the physician is seated comfortably, and without the bedside presence. Indeed, laparoscopic cases have been shown to result in less muscle fatigue than open surgeries [23] and robotic cases are less likely than other procedures to result in pain, numbness, or fatigue in surgeons [24]. The second time-out is therefore an opportunity for the surgeon to evaluate for progression of the operation as well as factors which are contributing to prolonged surgical duration.

Additionally, a second time-out can make the learning curve for robotic surgeries easier to overcome. Surgeons who are in the process of adopting robotic surgeries often explore the technology's feasibility and limitations [25]. This second time-out gives attending surgeons a chance to both identify the challenges and limitations contributing to extended operative times and reconsider the need to either convert to a different approach or seek input from another surgeon.

Finally, while robotic surgeries can be less physically demanding than open or laparoscopic approaches, extended surgical times can still be physically and mentally taxing to both the attending surgeon and the surgical assistant. Indeed, two studies have shown that, despite decreased stress in robotic compared to laparoscopic surgery, the former is associated with poorer surgeon performance $[26,27]$. Thus, the second time-out is an

\begin{tabular}{|ll|}
\hline Nerve & Recommendations \\
\hline Facial & Avoid overly tight facial anesthesia mask \\
\hline Ulnar & $\begin{array}{l}\text { Mildly supinate arm; do not pronate } \\
\text { Pad elbow } \\
\text { Avoid flexion greater than } 90^{\circ}\end{array}$ \\
\hline Brachial plexus & $\begin{array}{l}\text { Avoid stretching or overextension of arms } \\
\text { Use nonsliding mattress } \\
\text { Place shoulder braces, if used, on acromio-clavicular } \\
\text { joint } \\
\text { Do not tape chest too tightly }\end{array}$ \\
\hline Common peroneal & Avoid pressure between fibular head and leg support \\
\hline Saphenous & $\begin{array}{l}\text { Avoid pressure between medial tibial condyle and leg } \\
\text { support }\end{array}$ \\
\hline Obturator and femoral & $\begin{array}{l}\text { Flex hips between } 80-100^{\circ} \\
\text { Abduct legs between } 30-45^{\circ}\end{array}$ \\
\hline & \\
\hline
\end{tabular}

Figure 2 Commonly damaged nerves and recommendations on how to avoid injury. 
opportunity for the surgical team to assess their mental and physical engagement, and the need for a brief break or change of surgical assistant.

\section{Anesthesia considerations}

Long duration surgeries are of particular anesthesia concern for several reasons. Not only is patient access limited once the robot arms are in place [28], but exaggerated Trendelenburg positioning and pneumoperitoneum have been shown to decrease venous outflow from the head, increase intraocular pressure, worsen ventilation-perfusion mismatch, and increase systemic catecholamine release [29]. Indeed, venous pooling in the head and neck during extended periods of Trendelenburg has resulted in laryngeal edema [9]. In these cases, fluid volumes must be carefully monitored to decrease the risk of post-operative edema $[9,30]$. Pneumoperitoneum also decreases pulmonary compliance, vital capacity, and functional residual capacity [31,32], increasing the risk of hemodynamic and acid-base alterations over time [33,34]. To this end, the second time-out provides a chance to assess the overall trend of urine output during the case while also reviewing the trend of vital signs for instances where there is a slow deterioration.

Blood loss should also be of increased concern during extended periods of Trendelenberg positioning due to the danger of posterior ischemic optic neuropathy (PION), among other complications. While the exact mechanism of PION is unclear, excessive blood loss, hypotension, increased venous pressure, and increased ocular pressure are proposed factors, all of which can be increased in robotic surgeries [35]. While blood loss should ostensibly be closely monitored throughout the case, the second time-out offers an opportunity to formally review both the trend in blood loss over the case and to discuss with the surgeon whether blood loss is excessive and what steps, if any, should be undertaken to address the issue. Furthermore, the second time-out is a good time to redose antibiotics and draw necessary labs. Reports have shown that redosing of antibiotics significantly decreases the rate of surgical site infections, especially in surgeries which last longer than 4 hours [36,37]. Redosing, however, may be forgotten in longer operations; only approximately one out of five cases with extended surgical times receive antibiotic redosing [37]. The second time-out addresses this issue by establishing a reminder for antibiotic administration.

\section{Nursing considerations}

Engagement of the nursing staff in the second time-out is important, as they are optimally situated to check patient positioning and padding. Additionally, the second time-out is an opportunity for the nursing staff to adjust equipment which they might not have time or access to check during the operation. Indeed, equipment malfunction can account for nearly $7 \%$ of surgical conversions in some surgeries [38], highlighting the importance of ensuring that all equipment is in working order during long and complex cases. While checking surgical equipment, care should be taken to re-check that sequential compression devices (SCD) are on correctly and working. Extended surgeries, especially ones lasting more than three hours, put the patient at increased risk for thromboembolic events $[39,40]$, increasing the importance of pneumatic compression devices.

The second time-out is also an opportunity for nursing staff to verify surgical counts. Incorrect counts can be the most frequently reported adverse patient safety event during surgery [41], putting the patient at risk for multiple complications [42-44]. At the same time, case complexity and fatigue are significant risk factors for incorrect counts [44], putting surgeries with extended operative times at increased risk for incorrect surgical counts and highlighting the importance of a repeat count during the second time-out.

Lastly, the second time-out is a chance for nursing staff to update the OR administration on the room time. Not only does this give administrators time to ensure that the $\mathrm{OR}$ is adequately staffed with specialized robotic trained nurses, but it also allows for general operational planning.

\section{Conclusions}

While robotic surgeries have many advantages, they also predispose to certain complications, especially those which stem from prolonged operative time. Simultaneously, longer robotic surgeries are becoming more prevalent as surgeons overcome the learning curve and attempt more complex cases. These long surgeries put a significant strain on nursing, anesthesia, and surgical staff in the OR. They also raise concerns which are often not an issue in shorter, non-robotic cases. To address these issues and facilitate inter-disciplinary communication, we have developed a comprehensive checklist to be conducted during a "second time-out" three to four hours after the beginning of the case.

At our institution, we have rolled out the second timeout on a preliminarily basis over the last year by asking surgeons to adopt it on a voluntary basis. A select group of surgeons utilizing the second time-out have expressed positive feedback so far. Our initial experience has demonstrated a relatively minimal intrusion to the case time for the second time-out to be performed (Can be as little as a few minutes to complete it). As such, we are continuing to accrue further feedback prior to proposing greater adoption. Ongoing studies are being performed to evaluate its effectiveness.

Future considerations regarding the second time-out include further check-points conducted at regular 
intervals after the second time-out has been conducted, as a way to ensure continued reflection and communication in cases which extend much further than 3-4 hours. Furthermore, based on the results of our ongoing studies regarding the effectiveness of the second time-out in robotic cases, this concept can potentially be applied to all prolonged surgeries.

\section{Competing interests}

The authors declare that they have no competing interests

\section{Authors' contributions}

JS contributed to acquisition of data, as well as analysis and interpretation of data. JS also was involved in drafting the manuscript with revisions critically for important intellectual content. GV and JM were involved in drafting the manuscript with revisions critically for important intellectual content.

SB contributed to conception and design, analysis and interpretation of data. SB was also involved in drafting the manuscript and revising it critically for important intellectual content. All authors read and approved the final manuscript.

Received: 14 April 2013 Accepted: 30 May 2013

Published: 3 June 2013

\section{References}

1. Su L-M, Smith JA Jr: Laparoscopic and robotic-assisted laparoscopic radical prostatectomy and pelvic lymphadenectomy. In Campbell-Walsh Urology. 10th edition. Edited by Wein JA, Kavoussi LR, Novick AC, Partin AW, Peters CA. Philadelphia, PA: W.B. Saunders; 2011:2830-2849.

2. Brunaud L, Ayav A, Zarnegar R, Rouers A, Klein M, Boissel P, Bresler L: Prospective evaluation of 100 robotic-assisted unilateral adrenalectomies. Surgery 2008, 144:995-1001. discussion 1001.

3. Talamini MA, Chapman S, Horgan S, Melvin WS: A prospective analysis of 211 robotic-assisted surgical procedures. Surg Endosc 2003, 17:1521-1524.

4. Wolanski P, Chabert C, Jones L, Mullavey T, Walsh S, Gianduzzo T: Preliminary results of robot-assisted laparoscopic radical prostatectomy (RALP) after fellowship training and experience in laparoscopic radical prostatectomy (LRP). BJU Int 2012(110 Suppl):64-70.

5. Yong DZ, Tsivian M, Zilberman DE, Ferrandino MN, Mouraviev V, Albala DM: Predictors of prolonged operative time during robot-assisted laparoscopic radical prostatectomy. BJU Int 2011, 107:280-282

6. Koç G, Tazeh NN, Joudi FN, Winfield HN, Tracy CR, Brown J a: Lower extremity neuropathies after robot-assisted laparoscopic prostatectomy on a split-leg table. Journal of endourology / Endourological Society 2012, 26:1026-1029.

7. Reisiger KE, Landman J, Kibel A, Clayman RV: Laparoscopic renal surgery and the risk of rhabdomyolysis: diagnosis and treatment. Urology 2005, 66(5 Suppl):29-35.

8. Awad H, Santilli S, Ohr M, Roth A, Yan W, Fernandez S, Roth S, Patel V: The effects of steep trendelenburg positioning on intraocular pressure during robotic radical prostatectomy. Anesth Analg 2009, 109:473-478.

9. Phong SVN, Koh LKD: Anaesthesia for robotic-assisted radical prostatectomy: considerations for laparoscopy in the trendelenburg position. Anaesth Intensive Care 2007, 35:281-285.

10. Weber ED, Colyer MH, Lesser RL, Subramanian PS: Posterior ischemic optic neuropathy after minimally invasive prostatectomy. Journal of neuroophthalmology: the official journal of the North American NeuroOphthalmology Society 2007, 27:285-287.

11. Haynes AB, Weiser TG, Berry WR, Lipsitz SR, Breizat A-HS, Dellinger EP, Herbosa T, Joseph S, Kibatala PL, Lapitan MCM, Merry AF, Moorthy K, Reznick RK, Taylor B, Gawande A a: A surgical safety checklist to reduce morbidity and mortality in a global population. N Engl J Med 2009, 360:491-499.

12. Kroll DA, Caplan RA, Posner K, Ward RJ, Cheney FW: Nerve injury associated with anesthesia. Anesthesiology 1990, 73:202-207.

13. Warner MA, Warner ME, Martin JT: Ulnar neuropathy: Incidence, outcome, and risk factors in sedated or anesthetized patients. Anesthesiology 1994, 81:1332.
14. Cheney FW, Domino KB, Caplan RA, Posner KL: Nerve injury associated with anesthesia: a closed claims analysis. Anesthesiology 1999, 90:1062-1069

15. Akhavan A, Gainsburg DM, Stock J a: Complications associated with patient positioning in urologic surgery. Urology 2010, 76:1309-1316.

16. Winfree CJ, Kline DG: Intraoperative positioning nerve injuries. Surg Neurol 2005, 63:5-18. discussion 18.

17. Coppieters MW, Van De Velde M, Stappaerts KH: Positioning in Anesthesiology. Anesthesiology 2002, 97:75-81.

18. Gainsburg DM, Wax D, Reich DL, Carlucci JR, Samadi DB: Intraoperative management of robotic-assisted versus open radical prostatectomy. JSLS: Journal of the Society of Laparoendoscopic Surgeons / Society of Laparoendoscopic Surgeons 2010, 14:1-5.

19. Scott Van Appledorn M, Costello AJ: Complications of robotic surgery and how to prevent them. In Robotic Urologic Surgery. Springer; 2007:169-178.

20. Mills J, Burris M, Warburton D: Positioning Injuries Associated with Robotic-Assisted Urologic Surgery. J Urol 2013.

21. White $E_{1}$ Crosse $M M$ : The aetiology and prevention of peri-operative corneal abrasions. Anaesthesia 1998, 53:157-161.

22. Liu F-C, Liou J-T, Hui Y-L, Hsu J-C, Yang C-Y, Yu H-P, Lui P-W: Chemical burn caused by povidone-iodine alcohol solution-a case report. Acta Anaesthesiol Sin 2003, 41:93-96.

23. Szeto GPY, Ho P, CW T a, Poon JTC, Tsang RCC, Cheng SWK: A study of surgeons' postural muscle activity during open, laparoscopic, and endovascular surgery. Surg Endosc 2010, 24:1712-1721.

24. Gofrit ON, Mikahail AA, Zorn KC, Zagaja GP, Steinberg GD, Shalhav AL: Surgeons' perceptions and injuries during and after urologic laparoscopic surgery. Urology 2008, 71:404-407.

25. Hanna EM, Rozario N, Rupp C, Sindram D, lannitti DA, Martinie JB: Robotic hepatobiliary and pancreatic surgery: lessons learned and predictors for conversion. Int J Med Robot 2013.

26. Berguer R, Smith W: An ergonomic comparison of robotic and laparoscopic technique: the influence of surgeon experience and task complexity. J Surg Res 2006, 134:87-92.

27. Smith WD, Berguer R, Rosser JC: Wireless virtual instrument measurement of surgeons' physical and mental workloads for robotic versus manual minimally invasive surgery. Stud Health Technol Inform 2003, 94:318-324.

28. Mariano ER, Furukawa L, Woo RK, Albanese CT, Brock-Utne JG: Anesthetic concerns for robot-assisted laparoscopy in an infant. Anesth Analg 2004, 99:1665-1667. table of contents.

29. Ghomi A, Kramer C, Askari R, Chavan NR, Einarsson Jl: Trendelenburg Position in Gynecologic Robotic-Assisted Surgery. J Minim Invasive Gynecol 2012, 19:485-489.

30. Conacher ID, Soomro NA, Rix D: Anaesthesia for laparoscopic urological surgery. Br J Anaesth 2004, 93:859-864.

31. Safran DB, Orlando R: Physiologic Effects of Pneumoperitoneum. Am J Surg 1994, 167(February):281-286.

32. Andersson $L E$, Bååth $M$, Thörne $A$, Aspelin $P$, Odeberg-Wernerman S: Effect of carbon dioxide pneumoperitoneum on development of atelectasis during anesthesia, examined by spiral computed tomography. Anesthesiology 2005, 102:293-299.

33. Meininger D, Byhahn C, Bueck M, Binder J, Kramer W, Kessler P, Westphal K Effects of prolonged pneumoperitoneum on hemodynamics and acidbase balance during totally endoscopic robot-assisted radical prostatectomies. World J Surg 2002, 26:1423-1427.

34. Gutt CN, Oniu T, Mehrabi A, Schemmer P, Kashfi A, Kraus T, Büchler MW: Circulatory and respiratory complications of carbon dioxide insufflation. Dig Surg 2004, 21:95-105.

35. Newman NJ: Perioperative visual loss after nonocular surgeries. Am J Ophthalmol 2008, 145:604-610.

36. Zanetti G, Giardina R, Platt R: Intraoperative redosing of cefazolin and risk for surgical site infection in cardiac surgery. Emerg Infect Dis 2001, 7:828-831

37. Steinberg JP, Braun BI, Hellinger WC, Kusek L, Bozikis MR, Bush AJ, Dellinger EP, Burke JP, Simmons B, Kritchevsky SB: Timing of antimicrobial prophylaxis and the risk of surgical site infections: results from the Trial to Reduce Antimicrobial Prophylaxis Errors. Ann Surg 2009, 250:10-16.

38. Daniel WT, Puskas JD, Baio KT, Liberman HA, Devireddy C, Finn A, Halkos ME: Lessons learned from robotic-assisted coronary artery bypass surgery: risk factors for conversion to median sternotomy. Innovations (Philadelphia, Pa) 2012, 7:323-327. 
39. Clarke-Pearson DDL, Dodge RKR, Synan I, McClelland RC, Maxwell GL: Venous thromboembolism prophylaxis: patients at high risk to fail intermittent pneumatic compression. Obstet Gynecol 2003, 101:157-163.

40. Jaffer AK, Barsoum WK, Krebs V, Hurbanek JG, Morra N, Brotman DJ: Duration of anesthesia and venous thromboembolism after hip and knee arthroplasty. Mayo Clinic proceedings Mayo Clinic 2005, 80:732-738.

41. Chappy S: Perioperative patient safety: a multisite qualitative analysis. AORN J 2006, 83:871-897.

42. Bani-Hani KE, Gharaibeh KA, Yagha RJ: Retained surgical sponges (gossypiboma). Asian J Surg 2005, 28:109-115.

43. Lincourt AE, Harrell A, Cristiano J, Sechrist C, Kercher K, Heniford BT: Retained foreign bodies after surgery. J Surg Res 2007, 138:170-174.

44. Rowlands A: Risk factors associated with incorrect surgical counts. AORN J 2012, 96:272-284.

doi:10.1186/1754-9493-7-19

Cite this article as: Song et al:: The second "time-out": a surgical safety checklist for lengthy robotic surgeries. Patient Safety in Surgery 2013 7:19.

\section{Submit your next manuscript to BioMed Central and take full advantage of:}

- Convenient online submission

- Thorough peer review

- No space constraints or color figure charges

- Immediate publication on acceptance

- Inclusion in PubMed, CAS, Scopus and Google Scholar

- Research which is freely available for redistribution 